\title{
A TRANSMISSÃO DE NOMES GAVIÃO: FABRICANDO PESSOAS E COLETIVIDADES (GAVIÃO PYHCOPCATI JI - AMAZÔNIA MARANHENSE)
}

\author{
MELO*1, Maycon \\ GAVIÃO**2, Paulo Belizário \\ Universidade Federal do Maranhão (UFMA) \\ Secretaria de Estado de Educação do Maranhão (SEDUC)
}

\section{RESUMO}

Os Gavião Pyhcopcati ji são um povo falante do tronco linguístico MacroJê, que vive na parte sudoeste do Estado do Maranhão, na Amazônia maranhense. Quando uma criança nasce, um conjunto de nomes pessoais lhe é transmitido, criando relações sociais com diferentes pessoas e grupos que irão perpassar toda sua vida e morte. $\mathrm{O}$ nome também vincula o indivíduo à esfera cerimonial, lhe atribuindo funções e posições específicas nas performances realizadas no pátio. Atualmente, muitos nomes são substituídos nas conversas cotidianas pelos nomes em português, o que parece ter colocado uma questão de ordem sócio-cosmológica e não apenas linguística aos Gavião. $\mathrm{O}$ artigo discute a transmissão de nomes entre os Gavião e a forma como está relacionada à construção de pessoas e de coletivos a partir de momentos ritualizados e fundamentais para a continuidade da vida.

Palavras Chave: Gavião Pyhcopcatiji. Onomástica. Transmissão de nomes. Amizade formal. Amazônia maranhense.

\section{ABSTRACT}

The Gavião Pyhcopcatiji is a people speaking of the Macro-Jê linguistic trunk that lives in the southwest part of Maranhão State, in the Maranhão

1 Mestre em Antropologia Social, doutorando em Ciências Sociais pelo Programa de Pós-Graduação em Ciências Sociais da Universidade Federal do Maranhão (UFMA), São Luís, Maranhão. E-mail: mayconmelodoc@gmail. com.

2 Licenciado em Educação Intercultural pela Universidade Federal de Goiás (UFG), Goiânia, Goiás. E-mail: jytcacu@hotmail.com. 
Amazon. When a child is born a set of names is what is transmitted, creating social relationships with different people and groups that will permeate all their life and death. The name even links the individual ceremonial sphere, the one assigning Functions and the characteristics of the performances performed in the courtyard. Today, many names are replaced in everyday conversations by Portuguese names, which seems to have placed a question of socio-cosmological order and not just linguistic to the Gavião. The article discusses a transmission of names between the Gavião and a way related to the construction of people and collectives from ritualized moments and fundamental for a continuity of life.

Key words: Hawk Pyhcopcatiji. Onomastics. Transmission of names. Formal friendship. Amazon Maranhão.

\section{INTRODUÇÃO}

Os Gavião Pyhcopcati ji $i^{3}$ são falantes do tronco linguístico Macro-Jê e são classificados na etnologia indígena produzida no Brasil entre os Timbira orientais (Nimuendaju,1944). Vivem na parte sudoeste do Estado do Maranhão, na microrregião de Imperatriz, localizados na Amazônia maranhense. O ambiente que habitam se constitui em uma faixa de contato entre a floresta amazônica e o cerrado do centro-oeste. A Terra Indígena Governador foi demarcada em 1978 e homologada em 1982, e compreende um espaço de 41. 644 hectares, localizada no município de Amarante do Maranhão, onde atualmente os Gavião vivem em dez aldeias as quais dividem o território com mais cinco aldeias Guajajará/Tenentehara.

Entre os Gavião Pyhcopcati ji os nomes pessoais criam relações sociais aos indivíduos a partir do nascimento. Os mesmos nomes os vinculam à esfera cerimonial por meio de metades e grupos cerimoniais, que por sua vez possuem prerrogativas que implicam na constituição de pessoas e de valores morais através da transmissão de nomes. Este artigo procura apresentar a transmissão de nomes

3 Optei em utilizar a grafia desenvolvida pelos professores indígenas gavião, que resulta de um estudo onde corrigiram o trabalho de missionários da New Tribes, que escreveram uma primeira versão da "língua Gavião e Krikati". As correções se deram no sentido de adaptar a escrita, baseada na pronúncia do povo Krikati, a pronúncia gavião das palavras. 
entre os Gavião e a forma como está relacionada à construção de pessoas e de coletivos a partir de momentos ritualizados ${ }^{4}$.

Para os Gavião o nome faz parte de um sistema de classificação baseado em um princípio dual onde cada indivíduo vai receber um conjunto finito de nomes, que varia no número de três a cinco, alguns bem mais, outros apenas um. De modo geral no caso dos Timbira o nome pessoal é um tipo de identificação individual que liga o indivíduo à aldeia (Ladeira, 1982). Entre os Krahô e Canela, Ladeira (1982) fala em quatro ou cinco nomes divididos em "aglomerados de nomes".

Ao receber um conjunto de nomes gavião o indivíduo é afiliado a uma das metades cerimoniais gavião, cyjcati ji (partido de cima, leste) ou harỹcati ji (partido de baixo, oeste). Também é pelo nome pessoal que homens e mulheres são ligados aos grupos do pátio me'capii (motivos verticais) e me'cajcỳr (motivos horizontais). $\mathrm{O}$ nome, o ato de nomear como veremos, vai dar vida social ao recémnascido ou ao recém-chegado nas aldeias gavião, parece que da mesma forma como é para os Krikati, "naming, at one and the same time, takes a person out of the world of non-human, non-Krikati and places him in a social framework, whether he is newborn or newcomer" (Lave, 1967:142).

Na ausência de relações de parentesco é através do nome que visitantes e anfitriões encontrarão em outras aldeias e em outros povos Timbira suas posições no contexto cerimonial e social (Ladeira, 1982). A relação entre nominador (quem dá o nome) e nominado (quem recebe o nome) vai implicar um tipo de identidade entre eles, vai estender os termos de parentesco usados pelo primeiro ao segundo, consequentemente vai implicar em novos relacionamentos para o nominado. "Receber um nome - um nome timbira, por suposto é, pois adquirir, pelo menos virtualmente, "parentes" timbira (isto é, humanos), além de relações cerimoniais (amizade formal) e posições (prerrogativas) rituais" (Coelho de Souza, 2002: 428).

4 Este artigo escrito em coautoria com o professor Paulo Belizário Gavião só foi possível graças ao seu empenho primeiro como interlocutor e depois como autor. Na verdade, foi um grupo de sábios os grandes responsáveis pela transmissão desses conhecimentos que chegaram até eles geração após geração. Especificamente na questão da transmissão de nomes, gostaríamos de destacar alguns nomes. São eles: Manoel Ribeiro (Pỳhcrỳn, Rop cỳ, Cu'cax), Dana Souza (Caapa, Tehre, Pjiêhcoxy, Caheh, Roppoh, Cryjxyr) e Maria José (Po’pooj, Precohpa, Põrecru, Hujwa). 
Quando fiz o senso dos nomes, nominadores e epônimos na Aldeia Governador, minha ideia inicial era atender em certa medida à preocupação de muitos idosos com quem conversei, que me diziam como os jovens usam com frequência os nomes em português no lugar dos nomes gavião, como deixam de usar os termos de parentesco e que temiam que isso fosse esquecido assim como o conhecimento e práticas a eles relacionados.

O conjunto de nomes transmitido, na verdade cada nome, pode ser um nome masculino ou um nome feminino. Há pessoas que possuem dois conjuntos de nomes, um masculino e outro feminino, já que tiveram dois nominadores, outros que possuem no mesmo conjunto de nomes, nomes masculinos e femininos, provavelmente de conjuntos de nomes que foram quebrados e reorganizados pelo nominador. Como, por exemplo, no conjunto de nomes Wuuhyh, Caaxwa, Juxtẽhn, Caxiiwyraapeh, Hẽhpru, Tepmy'tac, Jỳtcỳy, onde Wuuhyh, Caaxwa, Juxtẽhn, Caxiiwyraapeh, Hẽhpru são designativos masculinos, e Tepmy'tace Jỳtcỳy, designativos femininos. Ou, no conjunto de nomes Poohre, Wajtẽm, Cawee, Crẽe'crẽp, onde Crẽ 'crẽp é designativo masculino, e Poohre, Wajtẽm, Cawee, designativos femininos.

Além dos nomes masculinos e femininos, há indivíduos que possuem nomes que não são reconhecidos como nomes de "origem gavião", mas são "nomes krikati” e "nomes canela" que foram rearranjados entre os nomes gavião. Por exemplo, Crytre, Maraxe, Xutjẽh, Ẽhpiicryhj, Horõn, Carõocree, Pỳncree, Cocuj, Crẽh'tyx, onde os nomes Crytre, Maraxe, Xutjēh, Ẽhpiicryhj são nomes krikati, e Horõn, Carõocree, Pỳncree, Cocuj, Crẽeh 'tyx são nomes gavião. Ou os nomes Pyhcrỳn, Rop cỳ, Cu'cax, onde Pyhcrỳn e Cu'cax são nomes gavião, e Rop cỳyum, nome canela. Tanto em uma situação quanto na outra, houve dois nominadores, um entre cada grupo do nominado.

O conteúdo semântico dos nomes varia e está imbuído de uma capacidade de harmonizar características ambíguas entre os nomes, por isso é difícil traduzi-los. Muitos nomes se referem a animais (que vivem na terra, na água, no céu), vegetais (árvores e produtos da roça), partes de plantas (caule, folha, fruto), partes do corpo humano (cabeça, nariz, perna) e a ações (cantar, furar, quebrar, ralar, fazer barulho).

Alguns nomes são mais simples, fazem referência direta a animais e vegetais, como Ju'jut (tucano), Po'pooj (barata), Caahyh (amendoim). Outros são a junções entre dois substantivos, como 
Hỳccrũ (hỳc; s.gavião + crĩ; s.cabeça), Pỳrcỳ (pỳr; s.tora + cỳ; s.casca, couro), Tep hot (tep; s.peixe + hot; s.fruto). Outros a junção entre substantivo e verbo, como Pji'cohxy (pji; s.terra + cohxy; v.cheirar), Cwyrpre (cwyr; s.farinha + pre; v.amarrar) e outros bem mais difíceis de traduzir, como Pỳtcacwỹh (pýt; s.tamanduá + cacwỹh, v.bater).

Segundo os cantores gavião, os animais da floresta (pryyhre) são responsáveis por terem ensinado as músicas, as cantigas realizadas nos rituais para os Gavião e que lhes foram transmitidas desde os primeiros habitantes da terra. No entanto, nenhuma narrativa associou animais, ou qualquer tipo de vegetal, a um fundo mítico dos nomes pessoais gavião ao qual fazem referência semântica.

A "impressão é que o padrão nome adquirido junto a animais (ou espíritos) por um ancestral mítico e desde então retransmitido deve ser geral", tanto em outros Jê (Coelho de Souza, 2002:571), quanto no caso dos Gavião. Quando perguntava aos idosos de onde os Gavião aprenderam seus nomes, quem e em que situação os ensinou, as respostas me levavam ao mito de Patjapii. O mito narra a dispersão e origem dos povos Timbira e Jê da região do Rio Grajau-MA.

Incomodada por ver seu povo sofrendo ao viver numa grande aldeia, que levava dias para ser atravessada e dificultava a relação entre os grupos, Patjapii teria separado aqueles que hoje conhecemos como povos Timbira e outros Jê por nomes/etnias e regiões diferentes (Sansão, 2011). Com a divisão, também teria atribuído uma língua própria a cada um deles. A origem dos nomes estaria associada às línguas que Pat japii deu a cada um destes povos, que por sua vez estariam relacionadas ao aspecto geográfico, tendo em vista a divisão feita no mito. Se essa é a origem dos nomes, vejamos agora como os Gavião fazem para manter seus próprios nomes e as implicações sociais que eles acarretam aos seus portadores e aqueles que lhes transmitem.

\section{Transmissão dos nomes gavião}

O conjunto de nomes que o indivíduo gavião ganha quando nasce, o mesmo que o associa às metades cerimoniais cyjcatiji (partido de cima, leste) ou harýy'catiji (partido de baixo, oeste), assim como aos grupos do pátio me 'cajcỳr (motivos horizontais) ou me'caapii (motivos verticais), é geralmente transmitido por completo. Há pessoas que receberam nome de mais de um nominador. Isso cria a possibilidade desse indivíduo pertencer a mais de uma das metades 
cerimoniais e dos grupos do pátio. Mas essa aparente discrepância não parece ser problema algum. O nome escolhido vai determinar a qual metade o indivíduo vai pertencer a partir de uma série de questões que são também contingenciais. No entanto, esse conjunto de nomes não é fixo e com o decorrer das transmissões as pessoas incorporam uns nomes no lugar de outros.

O sistema de transmissão de nomes gavião envolve em torno de três indivíduos. Participam aquele que recebe o nome (nominado), $\mathrm{o}$ indivíduo que efetivamente transmite o nome (nominador) e a pessoa que porta ou portava o nome transmitido (epônimo). No caso gavião haverá implicações sociais bem definidas entre o nominado, o nominador e o epônimo, como veremos em dois casos mais à frente. $\mathrm{O}$ nominador de ego masculino é geralmente alguém na geração ascendente e está para ele na categoria de êhnxii e tyhj (im, $\mathrm{m}, \mathrm{mm})^{5}$, mas em muitos casos se estende às categorias de crỹy tohm e êhnxõoh (Pm, P, PP, PPP).

Por sua vez, o epônimo de ego masculino será alguém na geração ascendente e está para ele na categoria de crỹ'tohm (Im, Pm, PPm), ou em alguns casos na categoria de ẽhnxõoh e crỹytohm (P, PP, PPP). O epônimo de ego masculino está para o nominado na categoria de quite. O nominador de ego feminino será alguém de geração ascendente na categoria de ẽhnxõoh e crỹ'tohm (IP, P, $\mathrm{PP})$, como em alguns casos será alguém na categoria de êhnxii e tyhj (m, mP, mm, mmm). O epônimo de ego feminino será alguém na categoria de tyhj $(\mathrm{mP}, \mathrm{iP}, \mathrm{mmP})$, ou em alguns casos na categoria de êhnxii e tyhj (m, mm, mmm). O epônimo de ego feminino está para o nominado na categoria de tyhj. ${ }^{6}$ Os nominados, tanto do sexo masculino, quanto feminino, estão para os epônimos na categoria de camỹjrõt (lit. aquele que carrega meu nome).

Parece que entre camỹjrõt e quite, assim como entre camỹjrõt e tyhj, existe uma profunda relação de respeito, como acontece entre os Krikati nos termos equivalentes (Lave, 1967:145). Em muitos casos o nominador é também o epônimo, mas em outros não, uma vez que a condição de epônimo entre os Gavião não se limita às categorias de crỹ'tohm (Im) para ego masculino e tyhj (iP) para ego feminino.

5 Foi adotada a seguinte convenção padronizada: $\mathrm{m}=$ mãe; $\mathrm{P}=$ pai; i=irmã; $\mathrm{I}=$ irmão; f=filha; $\mathrm{F}=$ filho; Im=irmão da mãe; $\mathrm{iP}=$ irmã do pai; e=esposa; $\mathrm{E}=$ =sposo.

6 O mesmo termo usado para $\mathrm{mP}, \mathrm{iP}, \mathrm{mm}$, eIm/eIP. 
Essa condição coloca em dúvida a centralidade da ideia do emparelhamento de germanos de sexo oposto para troca de nomes entre os Timbira orientais, como afirma Ladeira (1982). Quando irmãos de sexo oposto são emparelhados para transmissão de nome só homem dará à sua primeira filha o nome de sua irmã e a mulher dará ao seu primeiro filho o nome de seu irmão. A troca de nomes entre irmãos é vista como um tipo de modelo. Era assim que me explicavam os Gavião, mas, uma vez que não é uma regra, as possibilidades de nominação se abrem.

Seguindo esse raciocínio e comparando a transmissão de nomes entre os Timbiras orientais e os Apinajé, Giraldin (2000) percebe que se entre os primeiros a transmissão de nomes está relacionada à uma estratégia de estabelecer alianças entre os segmentos residenciais a partir da troca de nomes entre germanos do sexo oposto (Ladeira, 1982), no caso apinajé as alianças não se dão nos mesmo termos, já que não são os germanos de sexo oposto que irão trocar nomes, mas o "arranjador" que irá transmitir seus nomes ao nominado.

No caso gavião, sem a unanimidade da troca de nomes entre germanos de sexo oposto, a transmissão de nomes, mesmo assim, parece vinculada à ideia de criar alianças entre segmentos residenciais. Mas, como os nomes não são trocados apenas entre germanos de sexo oposto, o que implicaria em relações pré-determinadas entre o segmento da mulher e o do homem que se casam, as possibilidades de aliança parecem se abrir e encontrar fronteiras muito fluidas por via da transmissão de nomes. Mas, talvez, não tenha sido sempre assim. O processo de dispersão e contração das aldeias da década de 1980, separando segmentos e modificando drasticamente as possibilidades de casamento, pode ter contribuído para essa condição em se estabelecer alianças atualmente, que por sua vez, está relacionada à condição também pouco rígida da transmissão de nomes gavião.

Pelo o que pude perceber no senso dos nomes da Aldeia Governador os Gavião utilizam tanto seu estoque de nomes, digamos tradicionais, quanto aqueles de outros povos Timbira, como Krikati, Ramkokamekra/Canela. O senso em outras aldeias, ou uma etnografia mais detalhada sobre essa questão, provavelmente nos mostraria nomes Krahô no estoque de nomes gavião, já que no passado o fluxo entre estes povos era maior.

Além desse estoque de nomes tradicionais, os Gavião também manipulam a transmissão dos seus nomes em português, que segue 
basicamente o mesmo princípio que entre nós, preservando-se o sobrenome paterno. Talvez o grande indicativo dessa falta de rigidez que mencionei seja a forma como os apelidos assumiram o espaço dos nomes pessoais gavião entre os jovens e as crianças.

No início da pesquisa o interesse em registrar os nomes e termos de parentesco partia de uma demanda dos anciãos com quem conversava, que me diziam como os jovens estavam "deixando de lado" a língua gavião. Assim como ocorre com outros Jê do norte, como os Krahô, Krikati e Apinajé, os Gavião utilizam do recurso de chamar as pessoas por apelidos (Lave, 1967; Ladeira, 1982; Giraldin, 2000). A primeira forma de apelido que identifiquei se refere a um substantivo na língua gavião que foi tomado como nome pessoal. Como, por exemplo, Crẽhcapee (círculo periférico das casas), que é o apelido dado a Tepcapric, uma anciã que gosta de andar pelo círculo das casas passeando. Ou como o apelido Hapry (s; nome) dado a Cawcree, que é grande caçador, artesão e conhecedor da língua portuguesa por ter morado no Pará alguns anos.

Essa forma de apelido pode ser transmitida aos cognatos de geração descendente do portador, que compartilham, como ele, alguma característica relacionada ao apelido atribuído. Como aconteceu com a neta de Tepcapric, que, como gosta de andar pelo círculo periférico das casas como a avó, recebeu o mesmo apelido que ela, Crẽhcapee. A segunda forma de apelido são as palavras "gaviãonizadas", palavras do português que sofreram alteração na escrita e pronuncia pela língua gavião. Como o jovem que tem o apelido de Cone, já que gosta de beber e sempre que pode vai ao mercado Coronel que fica na cidade de Amarante do Maranhão atrás de bebida. Ou como o apelido de outra jovem, Sabohnit, que gosta de andar perfumada como a avó andava.

Em todas as variações os apelidos podem ser transmitidos aos parentes do portador. Mas, em nenhum dos casos que descrevi os apelidos são transmitidos formalmente aos indivíduos como são o conjunto de nomes que recebem de seus nominadores. O que não quer dizer que nomes Krikati e Ramkokamekra/Canela, como identifiquei no senso, passem pela mesma condição, já que parece serem incorporados no estoque de nomes gavião sem a mesma restrição aplicada aos apelidos.

Talvez ao incorporar nomes de outros povos os Gavião estejam, como os Apinajé que incorporam apelidos, preservando "a lembrança do portador daquele nome". A capacidade que os Gavião 
possuem em adaptar nomes que, talvez, não façam parte de seu repertório tradicional de nomes, se é que existe um, assim como a relevância, quase unanimidade, dos grupos domésticos nas formas atuais de transmissão dos nomes, deixam latente o que Ladeira (1982: 39) chama de "política de não perder nome".

\begin{abstract}
Um nome masculino, por exemplo, que não tenha sido adotado devido à morte de seu possuidor, será atribuído pelas suas parentes matrilaterais a um menino do mesmo segmento residencial, para que ele continue o processo de transmissão interrompido. A política de "não perder o nome" significa a política de não perder a possibilidade de sua transmissão, quer dizer, a possibilidade de estabelecimento de relações com outro grupo doméstico (idem: 40)
\end{abstract}

No caso gavião também é facilmente identificável essa "política de não perder nomes", talvez a relevância dos grupos domésticos na transmissão, que acabam privilegiando seu segmento nesse momento, seja um bom exemplo dessa política. Usar o nome de pessoas do mesmo segmento que o seu é tornar sua metade cerimonial maior e mais forte, consequentemente desequilibrando relações que são estabelecidas entre as metades, principalmente relações cerimoniais, como as corridas de tora.

Uma vez que os nomes pertencem aos grupos domésticos, colocar o nome em alguém é uma forma de preservar o nome, "não deixá-lo acabar", porque, como me diziam, "a pessoa morre, mas o nome fica". Sempre que falava sobre a importância da transmissão de nomes muitas pessoas me diziam, "eu tenho que ficar no lugar do meu bisavô", que é alguém duas gerações acima de ego, ou, “eu fiquei no lugar daquele que tinha o meu nome e que morreu e quem ganhar o meu nome vai ficar no meu lugar quando eu morrer". Agora vejamos duas situações onde o conjunto de nomes é, de certa forma, confirmado cerimonialmente nos rituais gavião.

\title{
2. Confirmação cerimonial do nome
}

Essa designação, confirmação cerimonial do nome, foi evidentemente elaborada por mim, não partiu de nenhum interlocutor gavião. Talvez os casos que descreverei possam se aproximar do 
que diz Lea (2012: 234) sobre as implicações sociais dos "nomes bonitos" entre os Mẽbêngôkre (Kayapó), que necessariamente precisam ser confirmados em cerimonias específicas. Não há entre os Gavião "nomes bonitos" ou "nomes comuns", há sim, implicações cerimoniais específicas a cada conjunto de nome, bem como cerimonias que se diferenciam umas da outras pela dificuldade de realização; um dos motivos são os altos custos necessários para realizar algumas delas.

No entanto, tanto nessas duas situações que descreveremos, quanto em todo ritual gavião (amjõhquẽhn; s. festa, v. alegrar-se), as narrativas parecem indicar como nessas performances há algo que precisa ser terminado, porque um dia o epônimo do nominado começou da mesma forma como ele é instruído a fazer agora para que outros depois dele continuem fazendo, como se também confirmassem seus nomes nesse momento cerimonial. Nesse ponto a designação do nome não lembra apenas do epônimo, mas de uma cadeia de epônimos que viveram antes dele, assim como dos camỹjrõt que virão depois dele, o que se aproxima da reflexão sobre a "fonte dos nomes" entre os Mẽbêngôkre (Kayapó).

Quando alguém reflete sobre a fonte de seus nomes, o indivíduo pensa não apenas sobre seu epônimo pessoal[...] Tal pessoa é apenas um nhêhget ou kwatỳj numa longa fileira denhêhget e kwatỳj com o mesmo nome, que se estende no tempo (idealmente pelo menos), muito além de qualquer indivíduo que seja lembrado pessoalmente pelos parentes mais velhos do portador atual (Lea, 2012: 241)

Há só mais um ponto a mencionar nessa rápida explicação sobre a designação "confirmação cerimonial" do nome gavião. $\mathrm{O}$ valor do nome mẽbêngôkre está em pertencer à uma Casa de origem que o transmite. No caso gavião esse valor está em pertencer a um grupo cerimonial, as relações do pátio. Como ocorre com os objetos cerimoniais ligados aos nomes krikati, só quem tem o nome pode usá-lo no pátio (Lave, 1967). Nesse caso do nome gavião, só quem tem o nome pode realizar determinada cerimônia no pátio.

No caso gavião a transmissão do nome implica a realização de um pequeno cerimonial, que acredito ser um momento tanto de transmissão quanto de confirmação do nome, já que assim eram narrados por darem início a uma série de transformações acionadas 
nos rituais que remetem a um epônimo anterior na cadeia daqueles epônimos que compartilham o mesmo nome que o nominado.

A primeira destas cerimonias de confirmação do nome acontece quando a criança começa a andar e quando entra na puberdade, preparando-se para o futuro casamento. Estes momentos de confirmação cerimonial do nome levam hoje o nome em português de "batismo", assim como os epônimos são chamados de "madrinha" e "padrinho" e os nominados "afilhados".

A professora e pesquisadora Raquel Bandeira (Pỳnhỳc) fez sua pesquisa de conclusão de Curso de Licenciatura em Educação Intercultural (UFG), abordando os "batismos" gavião. A professora sabe como a palavra "batismo" é associada ao sentido que nós ocidentais damos a ela, mas usa o termo "emprestado", para se referir a um momento de instauração e confirmação do lugar que cada indivíduo deve ocupar no decorrer de suas vidas dentro da organização cerimonial e social gavião. Segundo Pỳnhỳc, a palavra em gavião que se aproxima desse sentido de "batismo" é tohõohtỳy (lit. se apresentar). Quando alguém que tem o conjunto de nomes específico a um determinado ritual o realiza, na condição e posição que lhe cabe, é como ele estivesse se "apresentando" para todos na aldeia, ocupando o lugar daqueles que vieram antes dele e indicando o local que os que vêm logo a frente dele devem ocupar.

No modelo ideal de transmissão de nomes gavião, como já foi dito, o irmão da mãe nomeia o filho e a irmã do pai nomeia a filha, mas independente da confirmação dessa relação entre irmãos emparelhados para trocar nomes, antes da criança nascer as possibilidades de nomes já são discutidas. Assim

quando uma criança nasce com o nome do tio ou tia, todo dia de manhã cedo a pessoa vem pegar a criança e fica mais ou menos 15 ou 20 minutos antes do sol nascer com ela no colo, depois quando a criança começar a andar a tyhj prepara tinta, que é urucu, tesoura para cortar cabelo, os pais da criança também já arrumam pacará, legumes, ai a tyhj leva a criança para sua casa quando chega o dia, ela vai cortar o cabelo, pintar a criança, cantar uma música homenageando-a, ai vai levar para os pais e eles entregam a comida e o pacará, depois disso a criança já está batizada, tudo é feito na casa mesmo (Raquel Bandeira (Pỳnhỳc), Aldeia Governador, áudio 16) 
Quando perguntei para Pỳnhỳc o motivo dessas visitas diárias ela disse que era algo como uma forma de respeito. Parece-me um momento onde por alguma forma de troca de substancias, tyhj e quite transmitem aos seus camỹjrõt parte daquilo que são através desses pequenos momentos onde convivem juntos. O professor e pesquisador Paulo Belizário (Jỳtcacu) também descreveu esse momento de confirmação do nome, só que na perspectiva de um nominador masculino.

Se eu tenho um filho e coloco o seu nome nele ele vai te chamar de quite e se coloco o nome da Pỳn Crỳn ele vai chamá-la de tyhj, e vocês dois vão chamálo de camỹjrõt, se você der o meu nome para o teu filho, minhas irmãs já vão saber, depois que soltar o umbigo todo dia de manhã cedo uma das minhas irmãs, ou minha mãe, alguma já ficava encarregada de pegar a criança no colo todo dia de manhã, mesmo se a criança estiver dormindo, durante uma hora ou mais, pode dar banho na criança e entregar pra mãe, todo dia assim, até que a criança começa a andar, ai os pais já sabem, tudo isso sem cortar cabelo da criança, ai os pais começam a preparar pacará, comida, pra despachar a mulher, chamam a mulher, ela vai pintar, cortar o cabelo da criança e pronto, acabou o processo. (Paulo Belizário (Jỳtcacu), Aldeia Governador, áudio 15).

É interessante como não é Jỳtcacu que visita seu camỹjrõt, mas suas irmãs, mãe ou tias. As visitas que se estendem desde a queda do cordão umbilical até quando a criança começa a andar são necessárias uma vez estabelecida essa relação entre nominador/ epônimo e nominado. A pintura corporal com urucu (pyh), que segundo outros interlocutores pinta todo o corpo da criança, assim como o corte de cabelo, marcam esse momento de transformação do status social do nominado, que está ascendendo a uma nova posição, está tornando-se um ser social, uma pessoa (Gavião, 2015).

A cerimônia acontece na casa do nominado e parte dela na casa do nominador/epônimo, que leva a criança até sua casa para ter o cabelo cortado e o corpo pintado. Ao entregar a criança aos pais com cabelos cortados e toda pintada, o nominador/epônimo recebe seu pacará (caax) cheio de alimentos como uma forma de 
pagamento pela formação via consubstancialização entre nominado e nominador/epônimo.

A segunda maneira de confirmar o nome cerimonialmente inicia-se, no caso do sexo feminino, geralmente logo depois da primeira menstruação, pois está relacionada com a transformação do status de criança para o de mulher, pronta para se casar e ter filhos.

\begin{abstract}
Depois disso já é outro batismo, se a menina crescer essa mesma tyhj prepara cinto de embira de tucum, e se for homem tem que estar preso, ai depois que sair vão colocar penas, corta o cabelo, ganha o capacete, ai o rapaz já está pronto para namorar e casar, a moça só quando ganha cinto, ai já está pronta, passa urucu e cinto, se a menina ficar presa no Ẽhjcreere ou no Ruruut, depois que soltar a tyhj vai colocar o cinto, ai está batizado (Raquel Bandeira (Pỳnhỳc), Aldeia Governador, áudio 16).
\end{abstract}

A nominada ficará em reclusão sem poder comer carne ou se banhar. No dia seguinte os pais e parentes mais próximos vão caçar, trazendo de pedaço em pedaço, em pequenas porções, carne para a menina comer. Antes de raiar o dia a tyhj começa a preparar sua camỹjrõt.

A nominada fica em pé sobre uma esteira feita de palha de buriti (pap). A sua frente atyhj, que com suas próprias mãos trançou o cinto de fio de tucum (êh 'pre), começa a colocá-lo no corpo da nominada. A jovem mantém as duas mãos espalmadas uma sobre a outra a altura da vagina, o cinto é colocado passando por acima das mãos. Enquanto a tyhj canta, segurando esticado o fio, a camỹjrõtgira em torno do próprio eixo para o cinto se enrolar ao seu corpo. A jovem ainda é pintada de urucu $(p y h)$, tem penas de gavião branco (hýctoocot) coladas sobre o corpo e o cabelo cortado. 


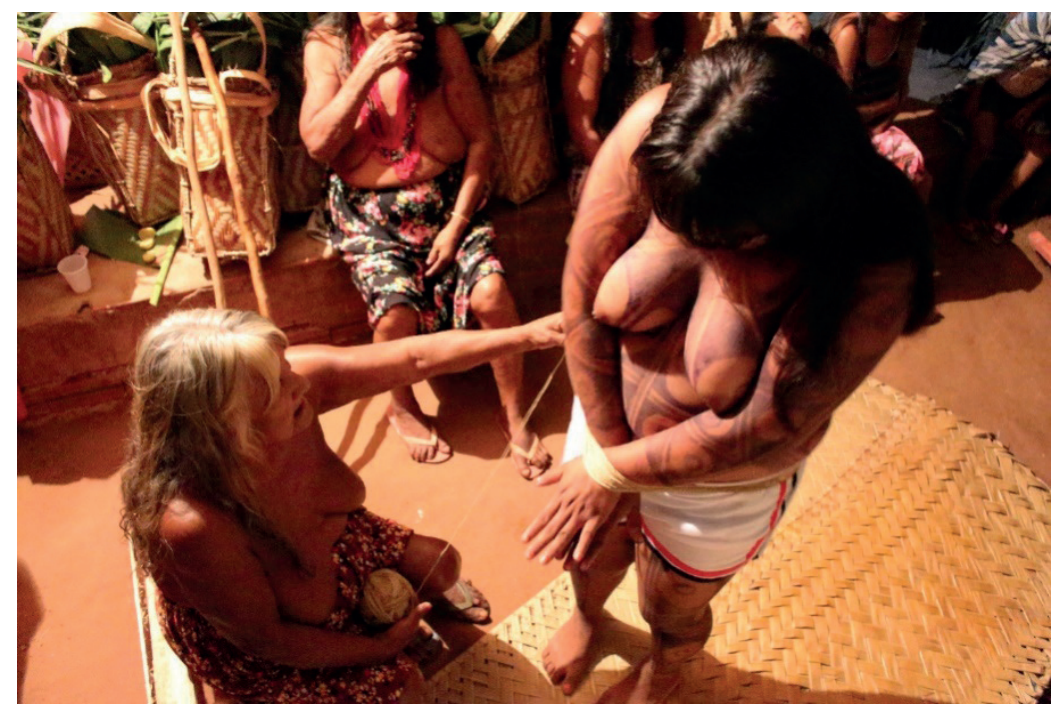

Foto 1- Ritual de Wyty, a tyhj coloca o cinto de fio de tucum (ẽh'pre) em sua camỹjrõt. Aldeia Governador. Foto: Maycon Melo, 2015.

No caso dos meninos eles participam dos rituais Ruruut e Êhjcreere, que não são restritos ao sexo masculino, os participantes estão definidos a partir do conjunto de nomes de cada indivíduo. No ritual de Ruruut, por exemplo, as jovens participantes também usarão o cinto de fio de tucum, além do adorno occipital feito com penas do rabo da arara (Pỳnjapyyh). Os jovens do sexo masculino usarão um "capacete", adorno occipital feito à base de algodão ou miçangas e penas (caxỳt). De modo geral, todos têm o corpo pintado de urucu e penas de gavião branco coladas sobre eles. 


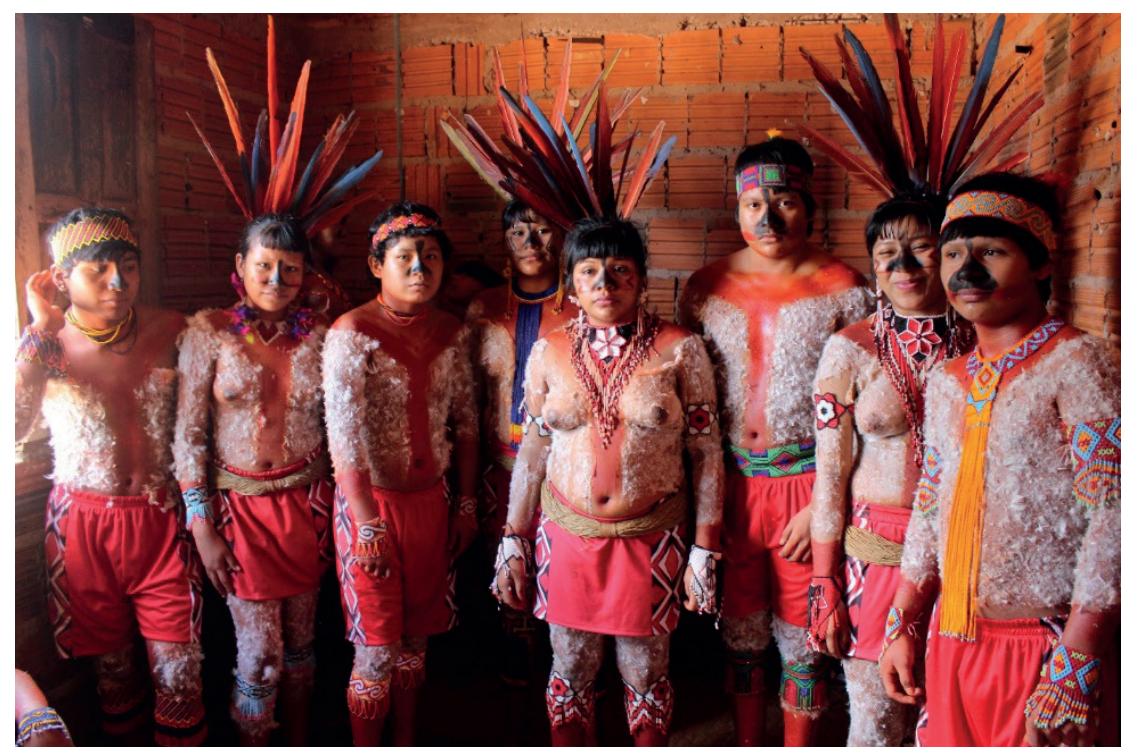

Foto 2 - Ritual de Ruruut (os ruruut). Detalhe de cinto (ẽh'pre) e do adorno occipital (pỳnjapyyh) para as mulheres, nos homens o adorno occipital (caxỳt). Aldeia Governador. Foto: Maycon Melo, 2016.

Não me descreveram destes momentos qualquer ato que pronuncie os nomes que, como venho argumentando, estão sendo confirmados nesses rituais. Nomes estão sendo confirmados, porque estão sendo "apresentados" (tohõohtỳy) a todos na aldeia. Só assim eles existem. De outra forma são esquecidos ou abandonados, assim como as relações que implicam. É só assim que o nominado ocupa o lugar dos epônimos que vieram antes dele.

Aqui novamente o caso gavião se aproxima dos mẽbêngôkre em relação ao tema dos nomes cerimoniais. "São nomes cerimoniais, não no sentido de serem usados em ocasiões cerimoniais, mas no sentido de serem associados a uma cerimônia especifica no qual são confirmados" (Lea, 2012: 245). A diferença, se posso dizer assim, é que no caso gavião todos os nomes são cerimoniais, já que todos pressupõem a realização de algum ritual.

\section{Amizade formal: hỳypẽhn e pẽhmxwyx}

Disse mais atrás que o conteúdo relacional dos nomes é a marca da alteridade e ponto de partida para se estabelecer relações, 
agora dentre elas a amizade formal é uma classe especial dessas relações. Também porque, como veremos, a amizade formal parece encarnar entre os Jê a dimensão da "afinidade potencial", da abertura daquilo que é exterior ao círculo das casas e ao parentesco, abertura a um "outro", que justamente por ser um "outro" é fundamental para constituição do eu, da transformação das sociedades ameríndias (Viveiros de Castro, 1993; Giraldin, 2011).

Como afirmou Carneiro da Cunha (1978), existem dois traços que marcam as relações de amizade formal entre os Timbira, a relação de respeito sob forma de evitação e de prestação mutua de serviços sob forma de solidariedade. Destes dois traços que a amizade formal compartilha com a afinidade, evitação e solidariedade, há ainda, com diferenças é claro, as relações jocosas de caráter sexual entre pessoas envolvidas com estas duas formas de criar relação.

No caso gavião se alter é masculino o termo para amigo formal é hỳypẽhn, se alter é feminino o termo épẽhmxwyx. Ego vai ganhar amigos formais de acordo com seu conjunto de nomes, ao transmitir nomes vai transmitir amigos formais. Ao que parece, como é entre os Krahô (Carneiro da Cunha, 1978), essa relação se construirá cotidianamente com o passar do tempo e pode facilmente ser rompida uma vez que os comportamentos esperados entre hỳypẽhn e pẽhmxwyx não se comprovem. Não necessariamente ser rompida, mas, digamos, abandonada, abandonam-se as regras de conduta e as relações que se estabelecem entre os amigos formais e seus parentes.

Parece ser unânime entre os Timbira orientais como a relação entre amigos formais é marcada pela evitação. Prevalece entre eles um respeito absoluto e intransponível, no caso gavião, isso ocorre ao menos quando ambos mantêm desde o início de suas vidas o comportamento esperado entre eles. Na Aldeia Governador o professor Paulo Belizário (Jỳtcacu) me descreveu como essa relação, mesmo com suas mudanças, ainda é presente, se com menos frequência nas relações cotidianas, é presente em grande parte dos contextos rituais. Jytcacu diz que

hoje crianças nem sabem quem são seus pẽhmxwyx, mas antes você não poderia nem dar oi, por exemplo, seu pẽhmxwyx vem para fazer uma pergunta para você, mas se tiver alguém do lado ela vai fazer uma conversa com essa pessoa [uma pergunta a essa pessoa], mas você vai entender e vai falar sem olhar para ele, minha pẽhmxwyx Janu, às vezes 
ela quer saber alguma coisa e vem aqui em casa, ai pergunta para Pỳncrỹ (esposa de Jỳtcacu), mas fala o nome do meu pai para se referir a mim, ai eu já sei que é comigo, a pẽhmxwyx sempre usa o nome do pai, da minha tia, nunca usa meu nome nem chega numa conversa comigo mesmo [...] (Paulo Belizário [Jỳtcacu]. Aldeia Governador, áudio 15)

Jỳtcacu identifica na relação entre amigos formais os mesmos aspectos da evitação que Carneiro da Cunha (1978) encontrou com os Krahô. Não se interpela um amigo formal, na verdade, nem se olha nos olhos de um amigo formal, é preciso, muitas vezes, desviar o caminho se um amigo formal vem em sua direção. Se não se fala com um amigo formal, tão pouco se pronuncia o nome dele, "os nomes do (a) amigo (a) formal não devem ser enunciados na sua presença ou na presença de seus parentes, pois causaria muita "vergonha", muito êh 'pahỳm a todos" (idem:77).

Causar "êh'pahỳm", por exemplo, pode ser motivo para que a relação entre os amigos formais seja rompida, ao menos entre os Krahô, "a simples inobservância da regra de evitação pode desfazer a relação". No caso gavião posso tomar o exemplo de Jỳtcacu como referência a essa questão do rompimento dos laços entre amigos formais. Ele começa sua narrativa me dizendo que hoje conversa com sua pẽhmxwyx, que as crianças não sabem quem são suas pẽhmxwyx, mas em seguida conta como a sua pẽhmxwyx, duas gerações ascendentes a dele, mantém os termos de evitação com ele.

Esse aparente esquecimento das relações entre amigos formais é desfeito nos momentos rituais, onde pela posição que ocupam nas performances, pẽhmxwyxe hỳypẽhn ficam em destaque a toda aldeia e assumem a outra faceta da relação entre ambos, a solidariedade mutua.

Quando tem brincadeira [ritual], sua pẽhmxwyx que fica no seu lugar, normalmente para ter bom comportamento no pátio quando acontecia alguma coisa todo mundo ia para o pátio levar castigo, se você não tiver pẽhmxwyx você apanha direto, mas quando tem ela chega perto e leva ela mesmo o castigo, as vezes que apanhei foi porque minha pẽhmxwyx não estava perto, pẽhmxwyxtem um papel importante, quando a gente é criança se baterem na gente alguém 
conta pra ela, ela canta, canta a noite toda em volta do pátio e vai cedo apanhar também, se um marimbondo de esporar ela canta, canta a noite toda em volta do pátio e vai lá também pegar o marimbondo, depois disso alguém tem que pagar para ela, se não pagar ai ela vai te cobrar[...] (Paulo Belizário [Jỳtcacu]. Aldeia Governador, áudio 15)

Nas pesquisas com os Jê do norte logo foi se percebendo que a amizade formal partilha com as relações de afinidade seus dois traços fundamentais: a solidariedade que deve uni-los e a evitação, que deve separá-los. Assim como a afinidade, a amizade formal compartilha também uma jocosidade de cunho sexual, não exatamente entre os amigos formais.

Carneiro da Cunha (1978) as chamou de "relações prazenteiras", no caso Krahô, geralmente com os pais, os filhos e os irmãos dos amigos formais que não podem revidar. "A amizade formal deve ser entendida como um complexo que abrange ao mesmo tempo uma estrita relação de evitação (com os amigos formais) e uma relação prazenteira (com certos parentes seus)" (idem: 83). A antropóloga ainda nos diz que nessa relação de evitação e de jocosidade sexual entre amigos formais é importante ainda a categoria de "estranho", de "estrangeiro". "Em seu duplo aspecto de evitação e parceria jocosa o amigo formal teria, portanto, esse caráter que me parece defini-lo, o de negar, de inverter, de contradizer, o de ser o antônimo" (Carneiro da Cunha, 1979: 34).

Vamos pensar com a autora, porque essa ideia de antônimo lança luz sobre o caso gavião. Ela nos diz que aos amigos formais é submetido o mesmo dano físico e moral que sofreu alter, "senão porque infringiu o dano ao antônimo é duplicar, reiterar a negação e o ataque, e recobrar assim a integridade inicial, que fora atingida". Diz também que sua presença em momento rituais está relacionada com o fato de ser o "outro", "então sua presença atesta a dissolução da personalidade [...] ao mesmo tempo, o confronto tese-antítese, nome-antônimo, conduz a síntese almejado no ritual, ou seja, ao novo status" de ser humano, de pessoa.

o amigo formal é conceitualmente o estranho, o outro e, enquanto tal, ele pode ser o mediador, o restaurador da integridade física e da posição social, graças aos jogos de dupla negação [...] Como se cada um desses 
grupos só se reconhecesse através de um jogo de espelhos que lhe devolve o seu contrário (idem: 38 ).

Mas, para Azanha (1980), Manuela Carneiro da Cunha não deixa claro em sua análise sobre a amizade formal, a relação que ele considera essencial que a categoria estabelece entre os "não parentes do parceiro", os "mecachkrit". Os amigos formais, na língua canela "mekritxwyy", são uma classe especial de "mecahkrit". A categoria, segundo o autor, indica um parâmetro para a pacificação do "outro", daquele considerado exterior ao plano do parentesco da aldeia. Mas, para ambos os autores, os amigos formais parecem condenados a continuar na mesma posição de "outro", uma relação baseada na evitação e solidariedade mutua.

\section{CONSIDERAÇÕES FINAIS}

A transmissão de nomes, assim como outras esferas da vida gavião, passa por transformações que tornaram mais frouxas as regras ideais de transmissão, mesmo elas ainda existindo em grande número dos nomes da Aldeia Governador. Mas, existem mudanças, como por exemplo, no peso que os grupos domésticos assumiram em decisões que deveriam envolver outras instâncias presentes na vida social e ritual dos povos Timbira, como os grupos de idade que parecem não existir mais entre os Gavião.

Os nomes pessoais estão ligados a sistemas de classificação mais amplos, a transmissão de nomes gavião envolve geralmente três pessoas e a dinâmica de suas relações, assim como nos termos de parentesco, está na capacidade de transformação dos termos uns nos outros e consequentemente nas relações que implicam entre pessoas e grupos diferentes. Essa capacidade relacional dos nomes é a marca da alteridade e ponto de partida para se estabelecer relações entre nominados, nominadores e epônimos, sejam da mesma aldeia, de aldeias diferentes ou mesmo entre povos diferentes.

Dentre essas relações aquelas entre amigos formais se destacam como uma classe especial. Se o amigo formal encarna a figura do "outro" como um espelho para a constituição de um novo status instaurado pela realização do ritual, configurando-se como um tipo de "mecanismo afinizador", tal capacidade não está apenas nas relações mediadas pela amizade formal, mas ao que parece em todo sistema de transmissão dos nomes gavião. 
É justamente na transformação dos termos e relações baseadas na transmissão de nomes, que são cambiantes e podem se transformar um no outro, aproximando ou afastando pessoas, que reside a capacidade de fabricar pessoas baseadas em valores morais e éticos, assim como a capacidade de fabricar grupos baseados em metades e grupos cerimoniais. A cada ritual (amjõhquẽhn; s. festa, v. alegrar-se) os Gavião atualizam e transformam os conhecimentos e as relações possíveis a partir da transmissão de nomes, garantindo a alegria e a sobrevivência de seu povo conforme aprenderam com os primeiros habitantes da terra.

$$
\text { Cỹh, xỳmpe. Fim. }
$$

\section{REFERÊNCIAS}

AZANHA, Gilberto. (1984). A forma Timbira: estrutura e resistência. Dissertação de mestrado - Programa de Pós-Graduação em Antropologia Social/Universidade de São Paulo.

CARNEIRO DA CUNHA, M. (1978). Os mortos e os outros: uma análise do sistema funerário e da noção de pessoa entre os índios Krahó. São Paulo: Hucitec.

. De amigos formais e pessoa: de companheiros, espelhos e identidades, in M. Carneiro da Cunha (org.). (1979). Antropologia do Brasil. Mito, história, etnicidade. Boletim do Museu Nacional, Série Antropologia, n. 32 .

COELHO DE SOUZA, Marcela. (2002) O traço e o círculo o conceito de parentesco entre os jê e seus antropólogos. Tese de doutorado - Programa de Pós-Graduação em Antropologia Social do Museu Nacional/Universidade Federal do Rio de Janeiro.

GAVIÃO, Paulo Belizário (2015). Levantamento Etnográfico dos Resguardos para o Povo Gavião - Pyyhcopcati ji pehxcrehjãarẽn. Trabalho de Conclusão de Curso - Graduação em Educação Intercultural - Ciências da Natureza/Universidade Federal de Goiás.

GIRALDIN, Odair. (2000). Axpên Pyràk. História, cosmologia, onomástica e amizade formal apinajé. Tese de doutorado - Programa de Pós-Graduação em Antropologia Social/Unicamp.

. (2011). Creating affinity. Formal friendship and matrimonial alliances among the Jê people and the Apinaje case.Vibrant (Florianópolis), v. 8-2, p. 403-426. 
LADEIRA, Maria Elisa. (1982). A troca de nomes e a troca de cônjuges: uma contribuição ao estudo do parentesco Timbira. Dissertação de mestrado - Programa de Pós-Graduação em Antropologia Social/Universidade de São Paulo.

LAVE, Jean E. Carter. (1967). Social Taxonomy among the Krikati (Jê) of Central Brazil. Unpublished Doctoral Dissertation, Havard University.

LEA, Vanessa R. (2012). Riquezas tangiveis de pessoas partiveis: Os Mẽbêngôkre (Kayapó) do Brasil Central. São Paulo. Editora da Universidade de São Paulo. Fapesp.

MELATTI, Júlio Cezar. (1978). O sistema social Krahô. Tese de doutorado - Faculdade de Filosofia, Ciências e Letras/Universidade de São Paulo.

SANSÃO, Jonas Polino. (2011). Festas Tradicionais do Povo Gavião: Pyhcop Cati Ji Jõ'amjõhquehn; Trabalho de Conclusão de Curso - Graduação em Educação Intercultural - Ciências da Linguagem/Universidade Federal de Goiás.

VIVEIROS DE CASTRO, Eduardo. (1993) “Alguns aspectos do dravidianato amazônico". In: E. Viveiros de Castro \& M. M. Carneiro da Cunha (orgs.). Amazônia: etnologia e história indígena. São Paulo: Núcleo de História Indígena e do Indigenismo da USP/FAPESP. pp 149-210 
